\title{
BMJ
}

\section{The influence of preoperative use of ventricular assist devices on survival after heart transplantation: propensity score matched analysis}

\author{
Jeffrey H Shuhaiber, assistant professor, ${ }^{1}$ Kwan Hur, research assistant professor, senior biostatistician, ${ }^{2,3}$ \\ Robert Gibbons, professor of biostatistics and psychiatry ${ }^{2}$
}

'Department of Cardiovascular Surgery, Cincinnati Children's Hospital Medical Center, University of Cincinnati, MLC 2004, Cincinnati, $\mathrm{OH}$ 45229-0309, USA

${ }^{2}$ Center for Health Statistics, University of Illinois at Chicago

${ }^{3}$ Center for Medication Safety, Pharmacy Benefits Management Services, Hines VA Hospital

Correspondence to: J Shuhaiber jeffrey.shuhaiber@gmail.com

Cite this as: BMJ 2010;340:c392 doi:10.1136/bmj.c392

\section{ABSTRACT}

Objective To determine the influence of the preoperative placement of a left ventricular assist device on survival after heart transplantation.

Design Prospective cohort study.

Setting Organ sharing database with patient level data on heart transplants in the United States.

Participants 2786 adults aged 18 or older in status $1 \mathrm{~A}$ or 1B (highest priority for heart transplantation with either some form of ventricular assist device, intravenous inotrope, or life expectancy of less than seven days), based on the United Network for Organ Sharing Registry, 1996-2004.

Main outcome measure Survival after heart

transplantation in patients who did and did not receive a left ventricular assist device.

Results The left ventricular assist device was not associated with decreased survival, even after the data were stratified by propensity score (the odds of being a treated patient). Inspection of the strata showed no difference in survival between patients who received the device and those who did not. The hazard ratios in strata 1 to 5 were $0.69,1.37,1.55,0.75$, and 1.19 , respectively, and none was statistically significant.

Conclusion Overall, survival after heart transplantation in patients who received a left ventricular assist device before transplantation was comparable to those who did not receive the device.

\section{INTRODUCTION}

Transplant centres worldwide are beginning to witness a plateau in the number of heart transplants as a result of stabilisation of the donor pool coupled with the increasing population of patients with end stage heart failure. Over time a larger proportion of patients waiting for heart transplantation will be bridged with left ventricular assist devices.

A left ventricular assist device is a battery powered, mechanical pump that is surgically implanted into the left ventricle and aorta. The device helps maintain the pumping ability of a heart that cannot work effectively on its own. The device fills directly from the heart and pumps into the aorta. Several types of device exist, and since 1996 there have been ongoing improvements in the design, size, and nature of the pump, with some providing a pulsatile flow into the aorta and others a continuous flow. As supportive therapy for patients with end stage heart failure who are not candidates for transplants, ventricular assist devices prolong survival. ${ }^{1}$ The role of these devices as a bridge to recovery or to transplantation has been clearly established since the late $1990 \mathrm{~s}$.

The indication for placement of a left ventricular assist device in a patient who is a candidate for transplantation is based on clinical decision, availability of a donor, and adequate psychosocial support. As such there is inherent selection bias because the use of a left ventricular assist device as a bridge to heart transplantation is determined by patient characteristics. It is known that placement of the device before heart transplantation improves clinical and metabolic function at the time of transplantation and improves survival without major complications up to six months after transplantation. Total costs are higher in patients who receive the device than those who do not, but average daily costs are similar. ${ }^{2}$ Several studies concluded that the left ventricular assist device improves the survival of patients after transplantation ${ }^{34}$ and advocate that it does not increase the rate of complications. Another study concluded that support for the device intensified the donor shortage by including recipients who would otherwise have not survived to transplantation. ${ }^{5}$ The implantation of the device favours patients who are large, have a diagnosis of ischaemic cardiomyopathy, have had multiple blood transfusions and complex cardiac operations, and are sensitised to human leucocyte antigen. Although patients with the device wait longer for a transplant than those who are classed as status 1 (the highest priority waiting for heart transplantation and either have some form of ventricular assist device, intravenous inotrope, or life expectancy of less than seven days) by the United Network for Organ Sharing Registry, they have similar post-transplantation hospital stay, operative mortality, and survival to those not requiring such support. ${ }^{5}$ However, such studies comprised small numbers of patients and failed to 
Table 1|Characteristics of patients who did or did not receive a left ventricular assist device before heart transplantation. Values are numbers (percentages) unless stated otherwise

\begin{tabular}{|c|c|c|c|}
\hline Variable & $\begin{array}{l}\text { No device group } \\
\quad(n=1432)\end{array}$ & $\begin{array}{l}\text { Device group } \\
\quad(n=1354)\end{array}$ & P value \\
\hline Sex (female recipient) & $333(23.3)$ & $200(14.8)$ & $<0.001$ \\
\hline Mean (SD) recipient age (years) & $51.7(12.6)$ & $50.6(11.4)$ & 0.01 \\
\hline Mean (SD) recipient body weight $(\mathrm{kg})$ & $78.9(17.0)$ & $86.2(17.4)$ & $<0.001$ \\
\hline \multicolumn{4}{|l|}{ Race: } \\
\hline African-American & $233(16.3)$ & $200(14.8)$ & 0.3 \\
\hline Hispanic or Latino & $121(8.5)$ & $51(3.8)$ & $<0.001$ \\
\hline Functional status* & $1249(87.2)$ & $1223(90.3)$ & 0.01 \\
\hline Admitted to hospital for medical condition & $938(65.5)$ & $909(67.1)$ & 0.4 \\
\hline Ventilator support after listing & $74(5.1)$ & $520(38.4)$ & $<0.001$ \\
\hline Transfusion after listing & $116(9.4)$ & $823(67.9)$ & $<0.001$ \\
\hline On life support & $59(4.1)$ & $140(10.3)$ & $<0.001$ \\
\hline Implantable defibrillator & $657(49.7)$ & $377(28.8)$ & $<0.001$ \\
\hline Positive for cytomegalovirus & $1112(77.7)$ & $991(73.2)$ & 0.006 \\
\hline \multicolumn{4}{|l|}{ Medical conditions: } \\
\hline Diabetes & $271(20.0)$ & $291(22.0)$ & 0.2 \\
\hline Chronic obstructive pulmonary disease & $46(3.4)$ & $42(3.2)$ & 0.7 \\
\hline Hypertension & $477(36.1)$ & $470(36.4)$ & 0.9 \\
\hline Dialysis & $33(2.6)$ & $82(6.3)$ & $<0.001$ \\
\hline Angina & $554(42.3)$ & $656(50.2)$ & $<0.001$ \\
\hline Infection requiring intravenous drug therapy & $146(11.5)$ & $424(33.4)$ & $<0.001$ \\
\hline Cerebrovascular disease & $40(3.0)$ & $47(3.6)$ & 0.4 \\
\hline Peripheral vascular disease & $42(3.2)$ & $43(3.3)$ & 0.9 \\
\hline \multicolumn{4}{|l|}{ Prescribed drugs: } \\
\hline Inotropes & $760(53.1)$ & $708(52.3)$ & 0.7 \\
\hline Antiarrythmics & $498(39.1)$ & $511(39.8)$ & 0.7 \\
\hline Amiodarone & $441(33.7)$ & $390(30.3)$ & 0.07 \\
\hline \multicolumn{4}{|l|}{ Primary diagnosis: } \\
\hline Coronary artery disease & $37(2.6)$ & $158(11.7)$ & $<0.001$ \\
\hline Cardiovascular disease & $1286(89.8)$ & $1158(85.5)$ & $<0.001$ \\
\hline Coronary heart disease & $43(3.0)$ & $4(0.3)$ & $<0.001$ \\
\hline Mean (SD) most recent serum creatinine concentration $(\mu \mathrm{mol} / \mathrm{l})$ & $123.1(66.6)$ & $125.7(65.2)$ & 0.3 \\
\hline Mean (SD) bilirubin concentration $(\mu \mathrm{mol} / \mathrm{l})$ & $26.8(65.5)$ & $19.6(21.1)$ & $<0.001$ \\
\hline \multicolumn{4}{|l|}{ Haemodynamic data: } \\
\hline Mean (SD) systolic pulmonary artery pressure $(\mathrm{mm} \mathrm{Hg})$ & $42.6(13.8)$ & $42.9(14.4)$ & 0.6 \\
\hline Mean (SD) diastolic pulmonary artery pressure $(\mathrm{mm} \mathrm{Hg})$ & $20.6(8.3)$ & $21.7(9.7)$ & 0.004 \\
\hline Mean (SD) pulmonary artery pressure $(\mathrm{mm} \mathrm{Hg})$ & $28.7(10.0)$ & $29.6(10.6)$ & 0.06 \\
\hline Mean (SD) pulmonary capillary wedge pressure $(\mathrm{mm} \mathrm{Hg})$ & $19.3(8.3)$ & $19.9(9.9)$ & 0.1 \\
\hline Mean (SD) cardiac output (mm Hg) & $4.4(1.6)$ & $4.7(1.6)$ & $<0.001$ \\
\hline Mean (SD) active days on waiting list (log) & $4.1(1.7)$ & $4.7(1.3)$ & $<0.001$ \\
\hline
\end{tabular}

*Limitations with activities of daily living.

adequately control for confounders. We compared the survival of patients classed as status 1 requiring a first heart transplant who received a left ventricular assist device with those who did not, adjusting for variation in case-mix due to possible selection effects.

\section{METHODS}

The database of the United Network for Organ Sharing Thoracic Registry includes details of heart, lung, and heart and lung transplantations carried out in the United States. The registry has demographic information on recipients and donors, ischaemia time, functional status measures, use of intra-aortic balloon pumps, ventilation after listing, medical comorbidities (dialysis for renal failure, chronic obstructive pulmonary disease, diabetes, and hypertension), use of a ventricular assist device, $\mathrm{ABO}$ blood type, recipient serum creatinine concentration, recipient serum bilirubin concentration, genetic compatibility (human leucocyte antigen), cause of donor's death (anoxia or cerebrovascular event or stroke), and cytomegalovirus infection (presence of any positive result for cytomegalovirus DNA, immunoglobulin G, immunoglobulin $\mathrm{M})$, and survival.

From among 35898 heart transplantations carried out on patients classed as status $1 / 1 \mathrm{~A} / 1 \mathrm{~B}$, we identified 2786 first heart transplantations done between 1996 and 2004 on patients aged 18 and older. We included patients with Heartmate (XVE Thoratec, CA) or Novacor (World Heart, UT) as a bridge device to transplantation. We did not include patients with the CardioWest (SynCardia Systems, AZ) system in this analysis as these devices are considered artificial heart systems. To minimise bias of right ventricular support we also excluded patients with Thoractec (Thoratec Laboratories, CA) and other temporary devices. All patients who received the left ventricular assist device retained the device until transplantation.

\section{Statistical analysis}

We compared baseline characteristics of patients who did and did not receive a left ventricular assist device, using two sample $t$ tests for continuous variables and the $\chi^{2}$ or Fisher's exact test for categorical variables.

To control for selection bias we carried out propensity score matching. ${ }^{6-8}$ The propensity score or "propensity score matching" is a general method used to adjust for selection effects in observational studies, whether or not randomisation was involved at any stage in the study. An estimate of the propensity score is typically obtained by regressing potential confounders on a binary indicator of treatment received (using discriminant analysis or logistic regression). The propensity score is the odds of being a treated patient conditional on the potentially confounding variables alone. The propensity score then may be used as the basis for stratification of the sample or in matching of the treated and control study participants or sometimes as a covariate in a regression model, although the first two approaches are less prone to residual bias. Once matched, bias is eliminated in probability for the set of covariates used in constructing the propensity score. In our analysis of these data we used propensity score matching based on a logistic regression and the covariates. Patients were assigned to one of five strata. The first stratum consisted of patients most similar to those who had a heart transplant but with no previous bridging by device (based on the potential confounders alone), and the last stratum consisted of patients most similar to those who had a left ventricular assist device before heart transplantation (regardless of whether they received the device as a bridge to transplantation).

Some of the variables had missing values and so we imputed those by using the complete sets of observed values as covariates for prediction purposes. ${ }^{9} \mathrm{We}$ 
Table 2 | Estimates and standard errors for variables included in propensity score analysis

\begin{tabular}{|c|c|c|c|c|c|c|}
\hline \multirow[b]{2}{*}{ Variable } & \multirow[b]{2}{*}{ Estimate } & \multirow[b]{2}{*}{ SE } & \multicolumn{2}{|c|}{$95 \%$ confidence limits } & \multirow[b]{2}{*}{$t$ test } & \multirow[b]{2}{*}{$P$ value } \\
\hline & & & Lower & Upper & & \\
\hline Intercept & -2.75 & 0.65 & -4.02 & -1.48 & -4.26 & $<0.001$ \\
\hline Transplant year (after 2000) & -1.61 & 0.20 & -2.00 & -1.21 & -8.01 & $<0.001$ \\
\hline Sex (female recipient) & -0.26 & 0.16 & -0.57 & 0.04 & -1.68 & 0.09 \\
\hline Recipient age (years) & -0.01 & 0.01 & -0.02 & 0.00 & -1.68 & 0.09 \\
\hline Recipient body weight (kg) & 0.02 & 0.00 & 0.01 & 0.03 & 4.90 & $<0.001$ \\
\hline \multicolumn{7}{|l|}{ Race: } \\
\hline African-American & -0.24 & 0.16 & -0.55 & 0.07 & -1.52 & 0.1 \\
\hline Hispanic or Latino & -0.90 & 0.25 & -1.40 & -0.41 & -3.60 & $<0.001$ \\
\hline Functional status* & 0.93 & 0.19 & 0.56 & 1.30 & 4.97 & $<0.001$ \\
\hline Admitted to hospital for medical condition & -0.25 & 0.12 & -0.49 & 0.00 & -1.98 & 0.05 \\
\hline Ventilator support after listing & 1.72 & 0.17 & 1.39 & 2.05 & 10.29 & $<0.001$ \\
\hline Transfusion after listing & 2.12 & 0.13 & 1.85 & 2.39 & 15.74 & $<0.001$ \\
\hline On life support & 0.63 & 0.23 & 0.19 & 1.07 & 2.78 & 0.01 \\
\hline Implantable defibrillator & -0.81 & 0.12 & -1.04 & -0.57 & -6.84 & $<0.001$ \\
\hline Positive for cytomegalovirus & -0.22 & 0.13 & -0.47 & 0.03 & -1.69 & 0.09 \\
\hline \multicolumn{7}{|l|}{ Medical conditions: } \\
\hline Hypertension & -0.20 & 0.12 & -0.45 & 0.04 & -1.65 & 0.1 \\
\hline Dialysis & -0.27 & 0.32 & -0.90 & 0.36 & -0.85 & 0.4 \\
\hline Chronic obstructive pulmonary disease & -0.37 & 0.31 & -0.98 & 0.24 & -1.19 & 0.2 \\
\hline Angina & 0.06 & 0.13 & -0.19 & 0.31 & 0.45 & 0.7 \\
\hline Diabetes & -0.05 & 0.15 & -0.33 & 0.24 & -0.31 & 0.8 \\
\hline Cerebrovascular disease & -0.06 & 0.33 & -0.72 & 0.60 & -0.18 & 0.8 \\
\hline Peripheral vascular disease & 0.08 & 0.33 & -0.57 & 0.73 & 0.24 & 0.8 \\
\hline \multicolumn{7}{|l|}{ Prescribed drugs: } \\
\hline Inotrope & -0.16 & 0.12 & -0.40 & 0.07 & -1.36 & 0.2 \\
\hline Infection requiring intravenous drug therapy & 0.58 & 0.17 & 0.24 & 0.92 & 3.43 & 0.001 \\
\hline Antiarrythmics & 0.26 & 0.16 & -0.05 & 0.57 & 1.64 & 0.1 \\
\hline Amiodarone & -0.14 & 0.15 & -0.44 & 0.16 & -0.92 & 0.4 \\
\hline \multicolumn{7}{|l|}{ Primary diagnosis: } \\
\hline Coronary artery disease & 1.77 & 0.37 & 1.03 & 2.50 & 4.73 & $<0.001$ \\
\hline Cardiovascular disease & 0.34 & 0.30 & -0.25 & 0.92 & 1.14 & 0.3 \\
\hline Coronary heart disease & -2.67 & 0.74 & -4.13 & -1.21 & -3.61 & $<0.001$ \\
\hline Most recent serum creatinine concentration $(\mu \mathrm{mol} / \mathrm{l})$ & -0.001 & 0.001 & -0.003 & 0.001 & -1.12 & 0.3 \\
\hline Bilirubin concentration $(\mu \mathrm{mol} / \mathrm{l})$ & -0.006 & 0.002 & -0.01 & -0.003 & -3.55 & $<0.001$ \\
\hline \multicolumn{7}{|l|}{ Haemodynamic data: } \\
\hline Diastolic pulmonary artery pressure (mm Hg) & 0.01 & 0.01 & -0.01 & 0.04 & 1.12 & 0.3 \\
\hline Systolic pulmonary artery pressure $(\mathrm{mm} \mathrm{Hg})$ & -0.02 & 0.01 & -0.04 & -0.01 & -2.78 & 0.001 \\
\hline Cardiac output (mm Hg) & 0.06 & 0.04 & -0.03 & 0.15 & 1.31 & 0.2 \\
\hline Pulmonary capillary wedge pressure (mm Hg) & 0.01 & 0.01 & -0.01 & 0.04 & 1.10 & 0.3 \\
\hline Mean pulmonary artery pressure $(\mathrm{mm} \mathrm{Hg})$ & 0.03 & 0.02 & 0.00 & 0.06 & 2.06 & 0.04 \\
\hline Active days on waiting list (log) & 0.24 & 0.04 & 0.15 & 0.32 & 5.68 & $<0.001$ \\
\hline
\end{tabular}

carried out multiple imputation $(\mathrm{n}=5)$ with a Markov chain Monte Carlo method, assuming a multivariate normal distribution for the data. A logistic regression model was used to develop a propensity score for each patient for each dataset. We then used the average propensity score to assign patients into one of the five strata.

We also carried out a 1:1 propensity score matching analysis as a sensitivity analysis. To create matched pairs we used a greedy matching procedure with calipers (width of propensity score intervals) of width 0.2 standard deviations of the logit of the propensity score and active days on the waiting list ( $\leq 30$ days $v>30$ days). With this procedure we matched the first randomly selected patient with a left ventricular assist device to one without the device, with the closest logit of the propensity score within a specified range (the caliper width). If several patients without the device were equally close to the patient with the device, then we randomly selected one of the patients without the device for matching to the patient with the device. We repeated this process until all possible matches were completed. If no patient without a device was available for a given 
Table 3 |Characteristics of participants by propensity score stratum. Values are numbers (percentages) unless stated otherwise

\begin{tabular}{|c|c|c|c|c|c|c|}
\hline \multirow[b]{2}{*}{ Variable } & \multicolumn{5}{|c|}{ Propensity stratum } & \multirow[b]{2}{*}{ Pvalue } \\
\hline & $\begin{array}{c}\text { First } \\
(n=558)\end{array}$ & $\begin{array}{l}\text { Second } \\
(n=557)\end{array}$ & $\begin{array}{l}\text { Third } \\
(\mathrm{n}=557)\end{array}$ & $\begin{array}{l}\text { Fourth } \\
(n=557)\end{array}$ & $\begin{array}{c}\text { Fifth } \\
(n=557)\end{array}$ & \\
\hline Sex (female recipient) & $184(33.0)$ & $106(19.0)$ & 94 (16.9) & $82(14.7)$ & $67(12.0)$ & $<0.001$ \\
\hline Mean (SD) recipient age (years) & $52.1(12.6)$ & $52.2(12.1)$ & $51.2(11.8)$ & $49.9(12.2)$ & $50.4(11.5)$ & 0.003 \\
\hline Mean (SD) recipient body weight $(\mathrm{kg})$ & $71.2(14.6)$ & $81.5(15.0)$ & $85.0(17.5)$ & $84.9(17.6)$ & $89.5(17.5)$ & $<0.001$ \\
\hline \multicolumn{7}{|l|}{ Race: } \\
\hline African-American & $109(19.5)$ & $81(14.5)$ & $80(14.4)$ & $78(14.0)$ & $85(15.3)$ & 0.07 \\
\hline Hispanic or Latino & $75(13.4)$ & $33(5.9)$ & $30(5.4)$ & $25(4.5)$ & $9(1.6)$ & $<0.001$ \\
\hline Functional status* & $463(83.0)$ & $491(88.2)$ & $512(91.9)$ & $503(90.3)$ & $503(90.3)$ & $<0.001$ \\
\hline Admitted to hospital for medical condition & $391(70.1)$ & $335(60.1)$ & $358(64.3)$ & $378(67.9)$ & $385(69.1)$ & 0.002 \\
\hline Ventilator support after listing & $3(0.5)$ & $11(2.0)$ & $37(6.6)$ & $141(25.3)$ & $402(72.2)$ & $<0.001$ \\
\hline Transfusion after listing & $9(1.6)$ & $23(4.1)$ & $131(23.5)$ & $368(66.1)$ & $530(95.2)$ & $<0.001$ \\
\hline On life support & $14(2.5)$ & $14(2.5)$ & $40(7.2)$ & $44(7.9)$ & $87(15.6)$ & $<0.001$ \\
\hline Implantable defibrillator & $351(62.9)$ & $272(48.8)$ & $186(33.4)$ & $177(31.8)$ & $107(19.2)$ & $<0.001$ \\
\hline Positive for cytomegalovirus & $456(81.7)$ & $452(81.2)$ & $384(68.9)$ & $388(69.7)$ & $423(75.9)$ & $<0.001$ \\
\hline \multicolumn{7}{|l|}{ Medical conditions: } \\
\hline Diabetes & $98(17.6)$ & $120(21.5)$ & $121(21.7)$ & $116(20.8)$ & $130(23.3)$ & 0.2 \\
\hline Chronic obstructive pulmonary disease & $23(4.1)$ & $14(2.5)$ & $17(3.1)$ & $15(2.7)$ & $19(3.4)$ & 0.6 \\
\hline Hypertension & $191(34.2)$ & $211(37.9)$ & $202(36.3)$ & $208(37.4)$ & $199(35.7)$ & 0.7 \\
\hline Dialysis & $7(1.3)$ & $13(2.3)$ & $17(3.1)$ & $33(5.9)$ & $50(9.0)$ & $<0.001$ \\
\hline Angina & $194(34.8)$ & $252(45.2)$ & $259(46.5)$ & $279(50.1)$ & $301(54.0)$ & $<0.001$ \\
\hline Infection requiring intravenous drug therapy & $32(5.7)$ & $66(11.9)$ & $109(19.6)$ & $160(28.7)$ & $267(47.9)$ & $<0.001$ \\
\hline Cerebrovascular disease & $15(2.7)$ & $15(2.7)$ & $15(2.7)$ & $18(3.2)$ & $24(4.3)$ & 0.5 \\
\hline Peripheral vascular disease & $16(2.9)$ & $17(3.1)$ & $15(2.7)$ & $15(2.7)$ & $22(4.0)$ & 0.7 \\
\hline \multicolumn{7}{|l|}{ Prescribed drugs: } \\
\hline Inotropes & $352(63.1)$ & $279(50.1)$ & $241(43.3)$ & $265(47.6)$ & $331(59.4)$ & $<0.001$ \\
\hline Antiarrythmics & $208(37.3)$ & $223(40.0)$ & $231(41.5)$ & $204(36.6)$ & $230(41.3)$ & 0.3 \\
\hline Amiodarone & $204(36.6)$ & $183(32.9)$ & $183(32.9)$ & $164(29.4)$ & $167(30.0)$ & 0.08 \\
\hline \multicolumn{7}{|l|}{ Primary diagnosis: } \\
\hline Coronary artery disease & $0(0.0)$ & $3(0.5)$ & $32(5.6)$ & $55(9.9)$ & $105(18.9)$ & $<0.001$ \\
\hline Cardiovascular disease & $483(86.6)$ & $530(95.2)$ & $502(90.1)$ & $485(87.1)$ & $444(79.7)$ & $<0.001$ \\
\hline Coronary heart disease & $38(6.80$ & $5(0.9)$ & $3(0.5)$ & $1(0.2)$ & $0(0.0)$ & $<0.001$ \\
\hline Received left ventricular assist device & $34(6.1)$ & $105(18.9)$ & $240(43.1)$ & $435(78.1)$ & $540(97.0)$ & $<0.001$ \\
\hline Death & $62(11.1)$ & $71(12.8)$ & $83(14.9)$ & $102(18.3)$ & $123(22.1)$ & $<0.001$ \\
\hline Mean (SD) most recent serum creatinine concentration ( $(\mu \mathrm{mol} / \mathrm{/})$ & $121.7(66.2)$ & $125.5(69.2)$ & $127.0(62.2)$ & $126.7(62.6)$ & $130.9(61.0)$ & 0.2 \\
\hline Mean (SD) bilirubin concentration ( $\mu \mathrm{mol} / \mathrm{l})$ & $37.6(91.2)$ & $23.6(27.0)$ & $26.1(30.9)$ & $24.6(31.6)$ & $19.0(18.9)$ & $<0.001$ \\
\hline \multicolumn{7}{|l|}{ Haemodynamic data: } \\
\hline Mean (SD) systolic pulmonary artery pressure $(\mathrm{mm} \mathrm{Hg})$ & $43.5(14.5)$ & $45.5(14.2)$ & $46.7(14.5)$ & $48.0(14.5)$ & $50.1(14.2)$ & $<0.001$ \\
\hline Mean (SD) diastolic pulmonary artery pressure $(\mathrm{mm} \mathrm{Hg})$ & $20.9(8.0)$ & $22.1(8.1)$ & $23.7(9.0)$ & $24.6(8.7)$ & $26.3(8.8)$ & $<0.001$ \\
\hline Mean (SD) pulmonary capillary wedge pressure $(\mathrm{mm} \mathrm{Hg})$ & $19.3(7.9)$ & $21.2(8.4)$ & $22.5(8.8)$ & $23.1(9.1)$ & $24.9(8.5)$ & $<0.001$ \\
\hline Mean (SD) pulmonary artery pressure (mm Hg) & $28.7(9.6)$ & $30.8(10.0)$ & $32.2910 .8)$ & $33.1(10.3)$ & $35.0(10.0)$ & $<0.001$ \\
\hline Mean (SD) cardiac output (mm Hg) & $3.9(1.3)$ & $4.2(1.3)$ & $4.2(1.4)$ & $4.4(1.5)$ & $4.4(1.4)$ & $<0.001$ \\
\hline Mean (SD) active days on waiting list (log) & $3.3(1.6)$ & $4.3(1.4)$ & $4.6(1.5)$ & $4.6(1.4)$ & $4.9(1.2)$ & $<0.001$ \\
\hline
\end{tabular}

patient with the device within the specified caliper width, then we excluded the patient with the device from the matched sample. We also excluded unmatched patients without the device from the matched sample. The distribution of each baseline characteristic for matched sample should be similar between the groups. We used standardised differences to examine the balance of the matched pairs. It has been suggested that a standardised difference of less than $10 \%$ represents meaningful balance. ${ }^{10}$
We used the Kaplan-Meier method to compare the distributions of survival and the log rank test to examine the differences in survival curves. Risk ratios were estimated using Cox proportional models, adjusting for donor related variables that were not included in the propensity score model (donor's age, sex, and weight; $\mathrm{ABO}$ blood type match; mismatch of human leucocyte antigen; ischaemia time (hours); and donor's cause of death). Data were analysed using SAS 9.13 software for Windows. 

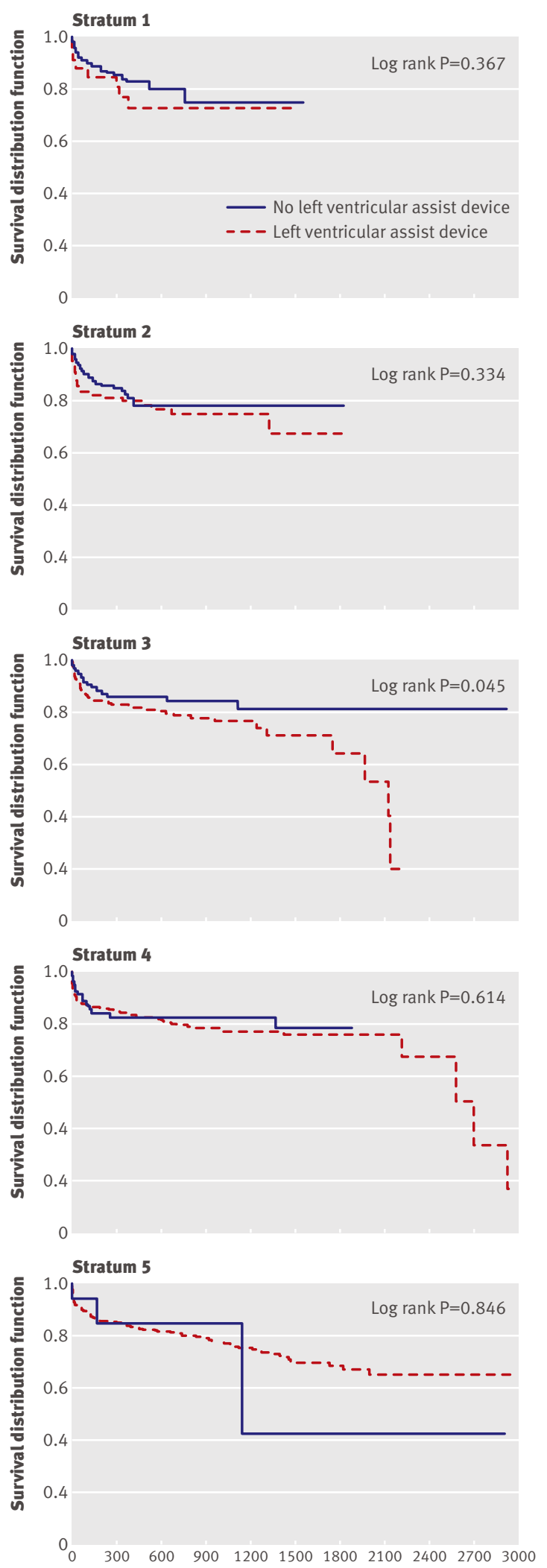

Days after implantation

Differences in Kaplan survival distributions between patients who received a left ventricular assist device and those who did not within each stratum. Stratum 1=patients most similar to those who had a heart transplant but no device; stratum $5=$ patients most similar to those who had a device before transplantation, with the other three strata being intermediate in terms of composition

\section{RESULTS}

Overall, 1354 patients received a left ventricular assist device and 1432 did not. Table 1 presents a simple univariate comparison of pre-transplantation characteristics between these patients. Women were less likely to receive the device before transplantation than men. Patients with the device were younger, less likely to be Hispanic, more likely to be on a ventilator or life support, more likely to have an infection requiring intravenous drug therapy, less likely to have an implanted defibrillator, more likely to receive transfusion, and had greater waiting times and higher rates of dialysis and angina (table 1 ).

Table 2 presents the variables that were included in the propensity score analysis, along with the regression coefficients and standard errors. Patients were more likely to receive a left ventricular assist device if they had a greater waiting time, a limitation with activities of daily living, an infection requiring intravenous drug therapy, a transfusion, a diagnosis of coronary artery disease or coronary heart disease, or were on a ventilator or life support.

Table 3 presents the results of the propensity score matching. In general, the higher strata (for example, strata 4 and 5) were populated with patients who had characteristics that most resembled those who would receive a left ventricular assist device. The proportion of patients who received the device were $6 \%$ (34) in the first stratum, 19\% (105) in the second, $43 \%$ (240) in the third, 78\% (435) in the fourth, and 97\% (540) in the fifth. The patients in the fifth stratum had an increased likelihood of being on a ventilator, having an infection requiring intravenous drug therapy, receiving transfusion, receiving dialysis, having angina, and being on life support. The patients in the fifth stratum were also more likely to be men and less likely to be Hispanic or Latino. The overall proportion of deaths were $11 \%(62)$ in the first stratum, 13\% (71) in the second, $15 \%(83)$ in the third, $18 \%(102)$ in the fourth, and 22\% (123) in the fifth.

Overall, the detrimental effects on survival after transplantation were not significant for patients who received a left ventricular assist device except in the third stratum (figure). In that stratum the number of patients with and without the device was more balanced (43\% v 57\%), and a significant difference in survival was observed. However, the observed difference in the third stratum was mainly due to a small number of deaths that occurred in the device group after five years. Given the lack of overlap between the two groups in the first and fifth stratum, these results should be interpreted with care. The analysis of Cox regression model after adjusting for the donor related variables also showed no significant difference between the two groups. Table 4 presents the hazard ratios and the corresponding 95\% confidence intervals within each stratum.

Results of the sensitivity analysis (1:1 propensity score matching) involved 518 matched pairs (518 patients from each group) for which the matched sample was well balanced on each variable (data not 
Table 4 | Hazard ratios by propensity score in each stratum

\begin{tabular}{lcccc} 
Stratum & Variable estimate & SE & P value & Hazard ratio $(95 \% \mathrm{Cl})$ \\
First & -0.371 & 0.658 & 0.6 & $0.69(0.19$ to 2.51$)$ \\
\hline Second & 0.314 & 0.342 & 0.4 & $1.37(0.70$ to 2.68$)$ \\
\hline Third & 0.437 & 0.311 & 0.2 & $1.55(0.84$ to 2.85$)$ \\
\hline Fourth & -0.284 & 0.358 & 0.4 & $0.75(0.37$ to 1.52$)$ \\
\hline Fifth & 0.176 & 1.014 & 0.9 & $1.19(0.16$ to 8.70$)$ \\
\hline
\end{tabular}

included). The matched analysis showed no difference in survival between patients who did and did not receive a left ventricular assist device (log rank $\mathrm{P}=0.08$; hazard ratio $1.18,95 \%$ confidence interval 0.75 to 1.86$)$.

To examine if the difference in the third stratum was due to the influence of a few patients with long follow-up periods, the analyses were repeated restricting the observation period to one year and then to five years. The analysis showed no significant differences in either short term (one year) or longer term (five year) survival.

Table 5 shows the diagnostic indications for transplantation between patients with and without a left ventricular assist device. The most common reason for transplantation was cardiomyopathy, accounting for more than $85 \%$ of the patients in both groups. Coronary artery disease was more common in the device group than in the no device group. However, congenital heart disease and valvular heart disease were more common in the no device group.

Of the 1354 patients who received a left ventricular assist device before transplantation, the date of receipt of the device was available for 957 patients. Because this variable was only collected after 2003, data for the entire original population could not be analysed. On average, time from receipt of the device to transplantation was 147 days (range 0-1240 days). The survival differences between patients who received a heart transplant within 30 days of receiving the device and after 30 days were compared using a log rank test. Survival was similar between the two groups, indicating no timing effect of the device on survival after transplantation.

\section{DISCUSSION}

In this study we adopted propensity score matching techniques to compare statistically similar subgroups of patients with and without left ventricular assist devices before transplantation - that is, we compared those patients who received the device with those who did not within strata of similar baseline characteristics except for receipt of a device. The survival rate after transplantation of patients with a left ventricular assist device was comparable to those without any bridge to transplantation. Although the log rank test showed a significant difference in survival in the third stratum $(\mathrm{P}=0.045)$, this was mainly due to the small number of deaths that occurred after five years in the device group. At five years survival between the two groups did not differ.

Overall, we found that survival after heart transplantation was not significantly lower for the device group compared with the no device group. The lack of overlap between patients who did and did not receive the device in the extreme strata (first and fifth) is an interesting result in itself, and points to the high degree of confounding and selection effects associated with patient characteristics and the receipt of a left ventricular assist device as a bridge to transplantation. This finding of hidden bias leads us to conclude that it is all but impossible to provide a simple comparison of survival between patients who do and do not receive a left ventricular assist device, either unadjusted or using covariate adjustment in a Cox regression model. This important methodological observation should help guide future research in this area.

\section{Comparison with other studies}

The decision to implant a ventricular assist device is based on several indices, including deterioration in haemodynamic variables or the unsuitability of a candidate for transplantation. Initial studies by the Cardiac Transplant Group and Registry of the International Society for Heart and Lung Transplantation showed that previous mechanical assistance had a significantly negative effect on survival. ${ }^{11}$ This area remains controversial given recent studies from several groups that showed comparable survival. In the absence of device related complications, optimal perfusion of end organs by adequate unloading of the heart and maximal circulatory support can be achieved. This provides an improved overall clinical status of recipients and smoother transition during transplantation and early recovery. Such patients can experience a considerable improvement in quality of life, with return to activities of daily living. One research team carried out a prospective, multicentre, non-randomised, controlled study to evaluate the left ventricular assist device as a bridge to transplantation. ${ }^{12}$ A total of 280 candidates at 24 centres were treated with Heartmate and compared with a historical control group of 48 patients not supported with a left ventricular assist device. Outcome measures were defined as laboratory data (haemodynamic, haematological, and biochemical), New York Heart Association functional class, and survival. The mean duration of support was 112 days, with 54 patients supported for more than 180 days. A total of 188 patients $(67 \%)$ were bridged to transplantation, and $10(4 \%)$ elected to have the device removed. Of the patients with the device, $82(29 \%)$ died before transplantation, compared with $32(67 \%)$ of the 48 control patients. Complications included bleeding, infection, neurological dysfunction, and thromboembolic events. Survival one year after transplantation was significantly higher in patients in the device group than in those in the control group: $158(84 \%) v 10(63 \%)$.

This result contrasts with a single centre in which 266 patients classed as status 1 by the United Network for Organ Sharing were successfully bridged to transplantation by either mechanical devices $(n=121)$ or inotropic support $(\mathrm{n}=145) \cdot{ }^{13}$ On the basis of their multivariable analysis with a Cox proportional hazard model, female 
Table $5 \mid$ Diagnostic category for heart transplants. Values are numbers (percentages) unless stated otherwise

\begin{tabular}{lccc} 
Diagnostic category & No device group & Device group & P value \\
Not reported & $26(1.8)$ & $15(1.1)$ & 0.2 \\
\hline Cardiomyopathy & $1286(89.8)$ & $1158(85.5)$ & $<0.001$ \\
\hline Coronary artery disease & $37(2.6)$ & $158(11.7)$ & $<0.001$ \\
\hline Retransplant or graft failure & $0(0.0)$ & $2(0.2)$ & 0.2 \\
\hline Valvular heart disease & $40(2.8)$ & $17(1.3)$ & 0.005 \\
\hline Congenital heart disease & $43(3.0)$ & $4(0.3)$ & $<0.001$ \\
\hline
\end{tabular}

sex was the only variable shown to be a statistically significant risk factor as a predictor for decreased survival after transplantation. Overall, both groups had similar survival rates after transplantation. However, the results of our propensity score matched study do not agree with previously reported registry data from the International Society for Heart and Lung Transplantation, which have consistently shown the presence of a left ventricular assist device to be a significant predictor of one year mortality (odds ratio $1.29 ; \mathrm{P}<0.001$ ) in a multivariable analysis. ${ }^{14}$

The propensity score matching strategy carried out in this study goes beyond any of the previously published reports in terms of adjusting for potential selection biases that can lead to a false association (or false lack of association) between receiving a left ventricular assist device and survival. Some investigators have examined the effect of the time interval between placement of the device and transplantation as a predictor of survival, with mixed results. One study compared 502 patients supported with a left ventricular assist device with 2514 patients receiving inotropic therapy between 1990 and 1997. ${ }^{3}$ They found no differences in survival after transplantation despite carrying out multivariable analysis to determine the importance of the time interval for using the device before transplantation. Another study, however, found a threefold higher perioperative mortality among those who received a transplant less than 30 days after implantation of a ventricular assist device, but survival at one year was similar. ${ }^{4}$ We examined the effect of placement time of a left ventricular assist device on survival in a subsample of 957 patients with a known date of placement. Survival was comparable between patients who received a transplant within 30 days of receiving the device and after 30 days suggesting that the time interval before heart transplantation did not influence survival.

Immunological sensitisation in recipients of left ventricular assist devices was observed in this study. The percentage of panel reactive antibodies before transplantation was higher in the device group than in the no device group $(16.5 \%$ v $8.6 \% ; \mathrm{P}<0.001)$. This is in agreement with other investigators that circulating antihuman leucocyte antigen class I and II antibodies occur more commonly in patients with left ventricular assist devices than in the population not supported by such devices. ${ }^{15} 16$

A mild improvement in renal function was seen in the recipients of a left ventricular assist device.
However, the baseline creatinine concentration was not significantly elevated in the groups of patients before transplantation or with the device studied in this cohort of patients. None the less, a left ventricular assist device provides effective perfusion to improve end organ function.

Application of a left ventricular assist device in the cardiac transplantation population was not evenly distributed on the basis of sex, age, and race. Patients who received the device were less likely to be Hispanic and more likely to be male; white; on a ventilator; have an infection requiring intravenous drug therapy; have pre-existing problems of diabetes, hypertension, or dialysis; to die, and to be significantly younger. These are important observations to the transplant community suggesting further work is needed to tackle this inequality of healthcare provision, especially when the Hispanic community is a growing minority in the United States.

\section{Strengths and limitations of the study}

The current study is based on a large population cohort and many data entry points for variables. The research question was clearly defined with distinct inclusion and exclusion criteria, as well as status on the heart transplant waiting list, study period, and type of device used, resulting in a relatively homogeneous study population. Variables included in the analysis were comprehensive, including those from recipients and donors.

This is a retrospective study, with the limitations associated with this type of study. Although we attempted to minimise bias through propensity score matching, hidden bias could potentially remain because relevant covariates were not available in the database of the United Network for Organ Sharing. Moreover, the database does not provide any data on peri-transplant morbidity with respect to rejection, pulmonary hypertension, renal dysfunction, ventilation, and stay in an intensive care unit. We hope that future randomised prospective studies will be carried out to alleviate these potential limitations. Another possible limitation of the study is that values for missing variables were imputed using a multiple imputation technique, which hinges on the assumption of values missing at random. If the assumption is violated, data generated by multiple imputation may introduce bias.

Finally, a possible bias might occur if the left ventricular assist device was associated with increased mortality during the transplantation itself. This was not the case. Sixty patients did not survive the operation, 30 of whom received the device and 30 of whom did not. All of these 60 patients were included in the survival analysis.

\section{Conclusions and policy implications}

Overall, survival after transplantation did not significantly differ between the device and no device groups. Inspection of the strata revealed no differences in survival between the two groups. In those strata within which the left ventricular assist device was more common (fourth and fifth), significant differences in survival were not observed. 


\section{WHAT IS ALREADY KNOWN ON THIS TOPIC}

Ventricular assist devices can prolong the life of patients with heart failure before transplantation

Studies have had mixed results in terms of survival benefit for left ventricular assist devices

\section{WHAT THIS STUDY ADDS}

Patients who received a left ventricular assist device had similar survival after transplantation to those who did not receive the device
Contributors: JHS and RG had the original idea for the study and designed and carried out the study. KH and RG did the statistical analysis. IHS wrote the first draft of the manuscript, which was edited by KH and RG. JHS is the guarantor. All authors had full access to all of the data (including statistical reports and tables) in the study and can take responsibility for the integrity of the data and the accuracy of the data analysis.

Funding: None

Competing interests: None declared.

Ethical approval: The University of Illinois waived the need for consent given that the study is based on a large dataset held by the United Network for Organ Sharing and no identity is revealed for any patient, surgeon, or hospital.

Data sharing: No additional data available.

1 Rose EA, Gelijns AC, Moskowitz AJ, Heitjan DF, Stevenson LW, Dembitsky W, et al. Long-term mechanical left ventricular assistance for end-stage heart failure. N Engl / Med 2001;345:1435-43.

2 Bank AJ, Mir SH, Nguyen DQ, Bolman RM 3rd, Shumway SJ, Miller LW, et al. Effects of left ventricular assist devices on outcomes in patients undergoing heart transplantation. Ann Thorac Surg 2000;69:1369-74.

3 Jaski BE, Lingle RJ, Kim J, Branch KR, Goldsmith R, Johnson MR, et al. Comparison of functional capacity in patients with end-stage heart failure following implantation of a left ventricular assist device versus heart transplantation: results of the experience with left ventricular assist device with exercise trial. J Heart Lung Transplant 1999;18:1031-40.

4 Ashton RC Ir. Goldstein DJ, Rose EA, Weinberg AD, Levin HR, Oz MC Duration of left ventricular assist device support affects transplant survival. J Heart Lung Transplant 1996;15:1151-7.
5 Massad MG, McCarthy P, Smedira NG, Cook D, Ratliff N, Goormastic M, et al. Does successful bridging with the implantable left ventricular assist device affect cardiac transplantation outcome? J Thorac Cardiovasc Surg 1996;112:1275-83.

6 Rosenbaum PR, Rubin DB. The central role of the propensity score in observational studies for causal effects. Biometrika 1983;70:41-55.

7 Rosenbaum PR, Rubin DB. Reducing bias in observational studies using subclassification on the propensity score. J Am Stat Assoc 1984;79:516-24.

8 Rosenbaum PR, Rubin DB. The bias due to incomplete matching. Biometrics 1985;41:103-16.

9 Rubin DB. Multiple imputation after 18+ years (with discussion). J Am Stat Assoc 1996;91:473-89.

10 Normand SLT, Landrum MB, Guadagnoli E, Ayanian JZ, Ryan TJ, Cleary PD, et al. Validating recommendations for coronary angiography following an acute myocardial infarction in the elderly: matched analysis using propensity scores. J Clin Epidemiol 2001;54:387-98.

11 Deng MC, Edwards LB, Hertz MI, Rowe AW, Kormos RL. Mechanical circulatory support device database of the International Society for Heart and Lung Transplantation: first annual report-2003. J Heart Lung Transplant 2003;22:653-62.

12 Frazier OH, Rose EA, Oz MC, Dembitsky W, McCarthy P, Radovancevic B, et al; HeartMate LVAS investigators. Left ventricular assist system. Multicenter clinical evaluation of the HeartMate vented electric left ventricular assist system in patients awaiting heart transplantation. J Thorac Cardiovasc Surg 2001;122:1186-95.

13 Morgan JA, Park Y, Kherani AR, Vigilance DW, Cheema FH, Oz MC, et al. Does bridging to transplantation with a left ventricular assist device adversely affect posttransplantation survival? A comparative analysis of mechanical versus inotropic support. J Thorac Cardiovasc Surg 2003;126:1188-90.

14 Hosenpud JD, Bennett LE, Keck BM, Boucek MM, Novick RJ. The registry of the International Society for Heart and Lung Transplantation: eighteenth official report-2001. J Heart Lung Transplant 2001;20:805-15.

15 Gonzalez-Stawinski GV, Atik FA, McCarthy PM, Roselli EE, Hoercher K, Navia JL, et al. Early and late rejection and HLA sensitization at the time of heart transplantation in patients bridged with left ventricular assist devices. Transplant Proc 2005;37:1349-51.

16 DeNofrio D, Rho R, Morales FJ, Kamoun M, Kearns J, Dorozinsky C, et al. Detection of anti-HLA antibody by flow cytometry in patients with a left ventricular assist device is associated with early rejection following heart transplantation. Transplantation 2000;69:814-8.

Accepted: 13 September 2009 